\title{
A SOCIABILIDADE DE BANHOS NO RIO GRANDE DO SUL
}

Do texto à inscrição no espaço (Villa Sequeira - 1890)

\section{Felipe Nóbrega Ferreira ${ }^{1}$}

\section{Introdução}

Ao longo da década de 1970, a disciplina de História diversificou suas abordagens, propondo deslocamentos em direção à filosofia, demografia, sociologia, e principalmente uma aproximação com a antropologia. Se, por muitos anos, as duas ciências crivavam suas diferenças, estabelecendo pontos de distanciamento, especialmente no que tange as fontes em que cada campo opera, é atual o debate de aproximação, propiciando, logo que os estereótipos foram deixados de lado, uma ação conjunta dentro do campo do conhecimento (Geertz, 2001).

Realizar essa aproximação não implica em negar as especificidades de cada área, suas metodologias particulares, mas sim operar um trabalho que coadune a narrativa histórica e a interpretação antropológica - encontrar pontos que possibilitem a criação de uma intriga histórica dentro de uma perspectiva de interlocução com a antropologia. Como afirma Geertz;

\footnotetext{
A junção da história e da antropologia não é uma questão de fundir dois campos acadêmicos num novo isto ou aquilo, mas de redefini-los em termos um do outro, administrando suas relações dentro dos limites de um estudo particular: as táticas textuais. (Geertz, 2001: 113)
}

No campo da história, O Grande Massacre de Gatos de Robert Darton (1986) tornou-se uma das referências no que tange essa aproximação dos dois campos. Ao interrogar-se sobre o referido massacre na França do século XVIII, e o fato disso provocar o riso daqueles que praticaram tal ato (operários de uma gráfica), Darton realiza uma importante contribuição nessa aproximação com a antropologia.

Em sua perspectiva, esse trabalho seria uma forma de conceber um "historiador etnógrafo", que seria aquele que:

Tenta descobrir sua cosmologia, mostrar como organizavam a realidade em suas mentes e a expressavam em seu comportamento. Não tenta transformar em filósofo o homem comum, mas ver como a vida comum exigia uma estratégia. (Darton, 1986: XIV)

\footnotetext{
${ }^{1}$ Universidade Federal do Rio Grande do Sul, Brasil.
} 
Nessa passagem, fica evidente a influencia da teoria da cultura de Clifford Geertz (1989), essa expressão individual que ocorre dentro de um idioma geral é para o historiador Robert Darton a pedra de toque de um método antropológico da história. $\mathrm{O}$ exercício do historiador nesse diálogo com a antropologia está nesse movimento do texto ao contexto e voltando, mais uma vez, ao primeiro, abrindo caminho através de um universo mental que lhe é estranho.

Pensando nesses termos, apresentamos nesse artigo uma reflexão antropológica que permita ao historiador explorar o caráter parcelar, não construído, das fontes brutas, para encontrar para lá da realidade manifesta uma realidade que se dá a ler. Assim, deixamos de lado os gatos de Darton e abrimos caminho para um litoral azul que se anuncia na forma de ribombo.

Uma praia na extremidade meridional brasileira é inaugurada no ano de 1889. Trata-se do Balneário Cassino ${ }^{2}$, localizado na cidade de Rio Grande. Notadamente, nos valemos de um documento/fonte intitulado "Guia dos Banhistas", o qual nos permite discutir a construção das práticas sociais dentro dessa que é a primeira estação de banhos do Estado.

\section{Uma praia em forma de texto}

Data de dezembro de 1889 a inauguração da temporada de banhos. E, ao chegar ao balneário, no mês de janeiro seguinte, logo ao descer das locomotivas, os excursionistas recebiam um guia para os banhos.

\footnotetext{
${ }^{2}$ Quando de sua inauguração chama-se Villa Sequeira, ou mesmo pode ser encontrada a referência Costa da Mangueira. Optamos aqui por trabalhar com o nome atual, Balneário Cassino, que foi estabelecido a partir da década de 1940.
} 


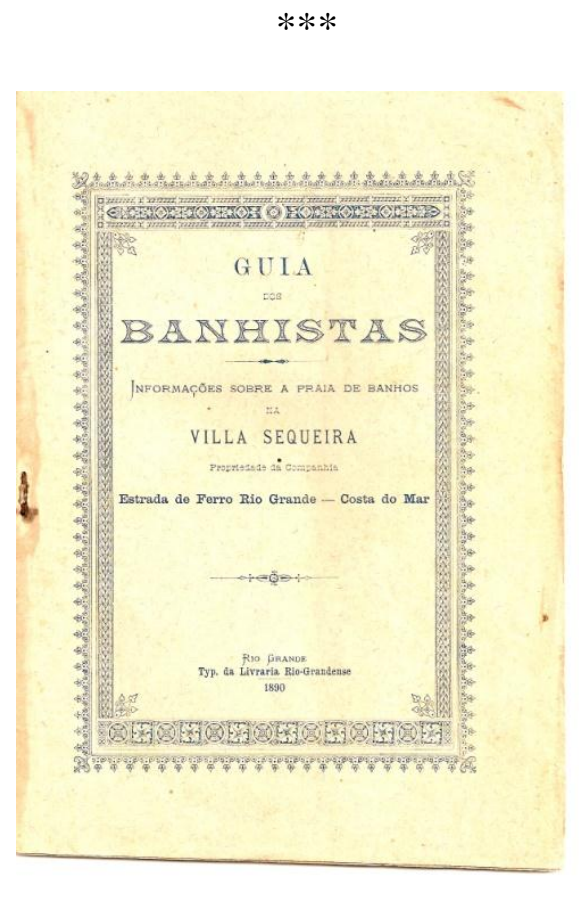

Imagem 1: Guia dos Banhistas.

Acervo da Bibliotheca Riograndense.

$* * *$

O "Guia dos Banhistas: Informações sobre a praia de banhos na Villa Sequeira" foi impresso no ano de 1890, pela Typographia da Livraria Rio-Grandense, cidade de Rio Grande. Caso não recebesse logo na chegada, os visitantes encontrariam o mesmo suporte no único hotel da localidade, o Hotel Casino (Enke, 2005).

O documento, constituído de 23 páginas, apresenta seis temas: Situação, Tratamento Maritimo, Precauções Hygienicas ${ }^{3}$, Commodidades na praia, Habitações na Villa Sequeira e Salão de Visitas e concertos, e de jogos. Sendo que, no interior de cada capítulo, existem subtítulos que organizam os assuntos a serem detalhados pelo manual.

\footnotetext{
${ }^{3}$ Optamos por manter a grafia da época.
} 


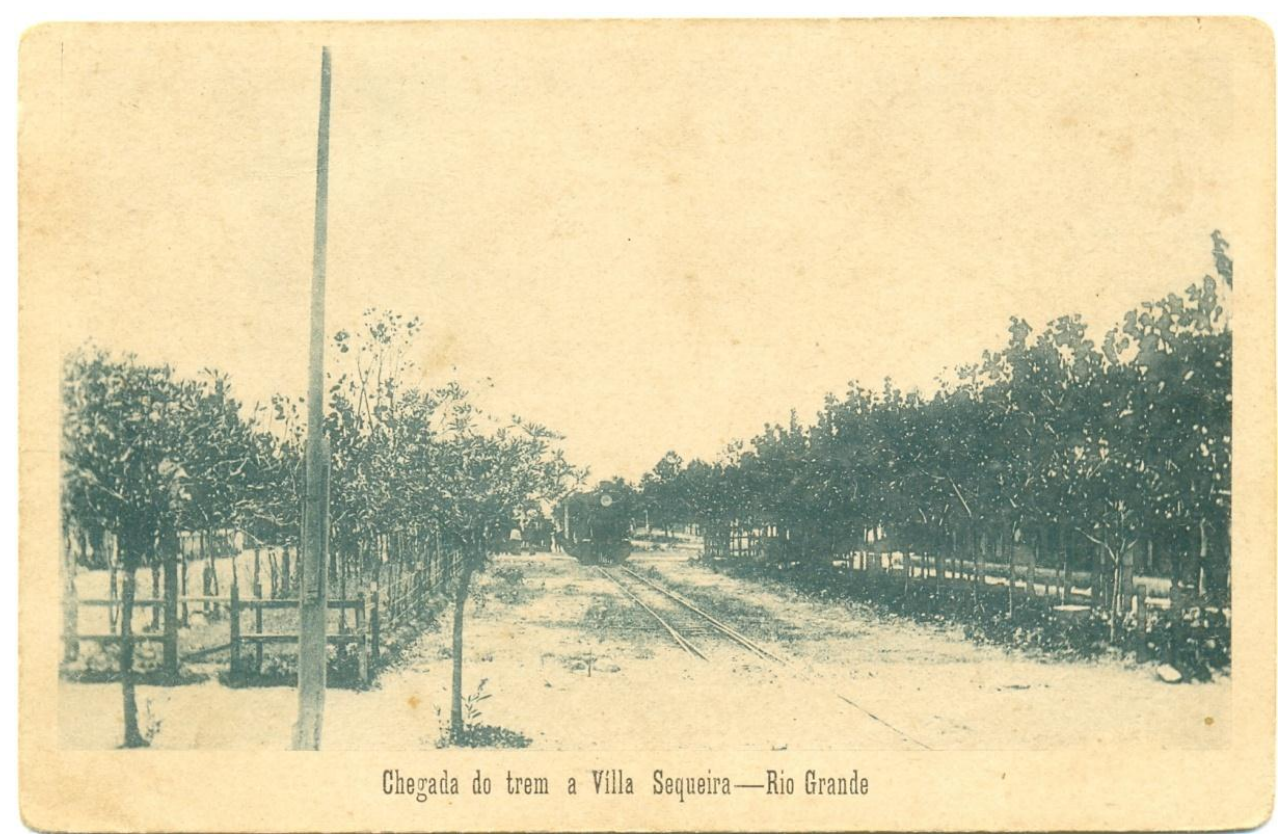

Imagem 2: Rua principal, 1908.

Acervo da Bibliotheca Rio Grandense.

No primeiro capítulo do guia, "Situação", existe uma descrição geográfica do lugar, em que se torna significativa a construção de uma longa alameda de 2200 metros de comprimento e 16 metros de largura é projetada. É nessa longa avenida que se dará o acontecer social do balneário, concentrando-se nessa área o hotel de veraneio, as mansões da burguesia citadina e o comércio local.

No segundo tópico, “Tratamento Maritimo", está relacionado os cuidados que os veranistas devem ter ao praticar o banho, especialmente no que diz respeito a alimentação:

Os almoços, tão usados em Portugal, de café com café com leite e pão com manteiga, são umas massas mais indigestas e mais affrontantes que se podem ingerir nos estômagos. Com isso, a refeição ideal seria $\mathrm{O}$ bife de vitella ou a costeleta de carneiro grelhada, os ovos quentes e uma pequena chávena de chá preto, ou simplesmente o bom leite fresco. $\left(\mathrm{GB}^{4}, 1890: 9\right)$

\footnotetext{
${ }^{4}$ Abreviatura que adotamos ao longo do trabalho para "Guia dos Banhistas" junto às citações.
} 
No tópico seguinte, "Precauções Hygienicas", são evidenciados os melhores horários para freqüentar a praia e praticar o banho - o horário da manhã como o ideal para o fortalecimento do corpo robusto. O período da tarde, por seu turno, deveria ser reservado para as "pessoas débeis", que tem na água já aquecida pelo sol mais forte alguma espécie de poder curativo para os seus frágeis corpos.

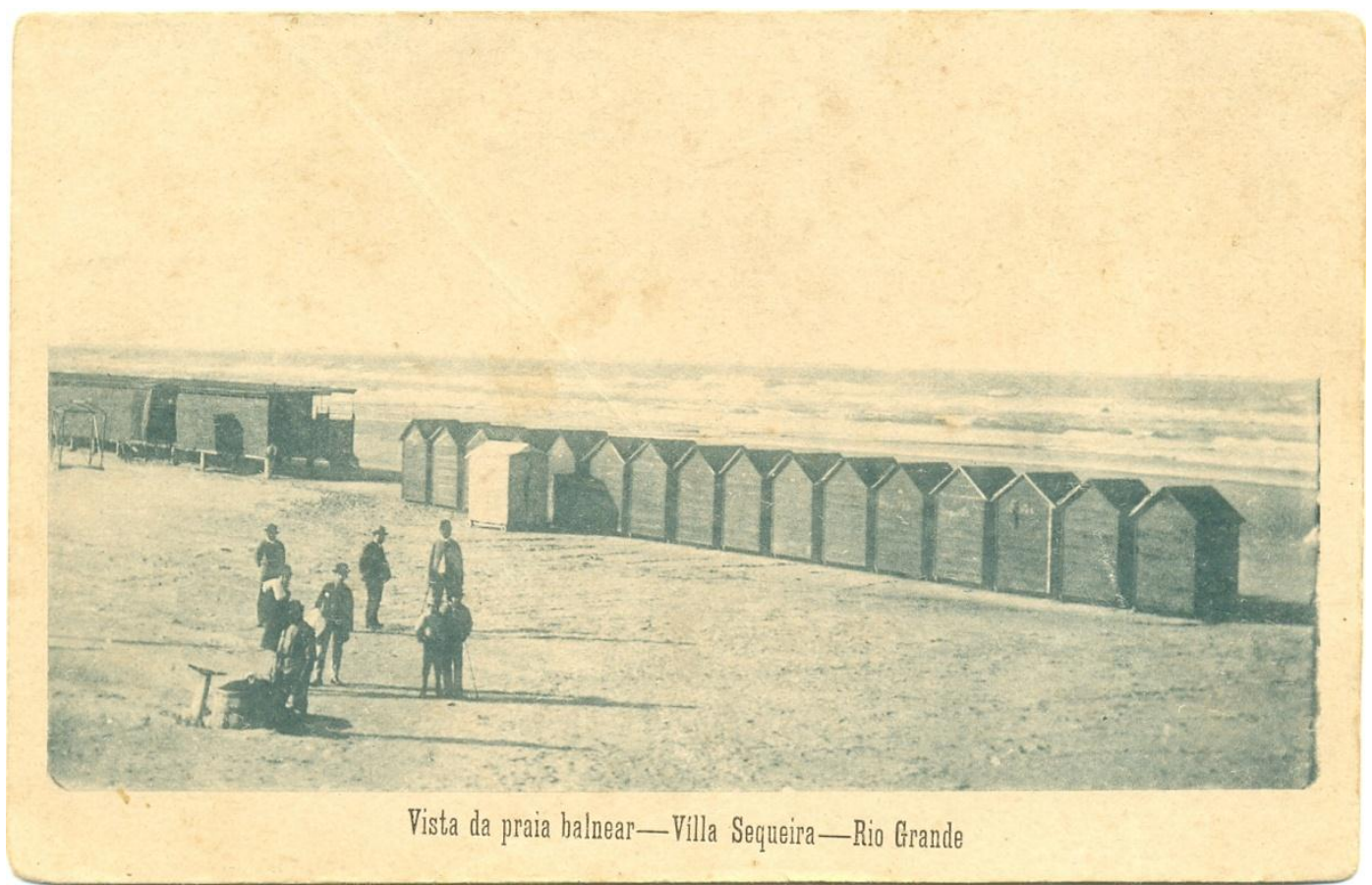

Imagem 3: Barracas e camarotes, 1908. Acervo da Bibliotheca Riograndense.

Ao entrar na água, o Guia aponta que a pele deve estar previamente aquecida, assim "um certo exercício moderado, um pequeno passeio a pé, ao sol, é muito útil" (GB, 1890: 12). Da mesma forma, sugere que não seria aconselhável ter o corpo nu contato com o ar por tempo prolongado, pois seria dessa forma que haveria exposição às constipações. Assim:

\footnotetext{
${ }^{5}$ Optamos por manter a grafia dos termos no original.
} 
É importante que o banhista ao chegar a barraca, se dispa com a máxima rapidez, enfie um calção de malha de lã, se evolva n'uma capa ou n'um plaid e corra immediatamente para a água, desembuçando-se no momento da immersão" (GB, 1890: 12)

Por fim, no momento da saída da água, aponta: "Depois do banho deve ser o corpo rapidamente friccionado como um lençol áspero até dar à pelle uma cor rosada" (G.B, 1890: 14).

Após os rituais do banho, o documento passa a referenciar aquilo que chama de “Commodidades na Praia”, evidenciando o número de camarotes disponíveis à beiramar. São 100 camarotes masculinos de $1^{\circ}$ classe e os mesmos 100 para senhoras. Uma segunda classe de camarotes contempla 20 para homens e 20 para mulheres. E aqueles que não possuem condições econômicas de usufruírem desse item, podem pagar um preço menor e utilizar umas das 50 barracas sobre rodas (G.B, 1890).

Em sua forma física, "Os camarotes são construídos com solidez e elegância sobre um estrado fixo sobre estacas de madeira de lei, com porta vidraça, xadrez para o piso, banquinho, cabides para roupa, e espelho" (GB, 1890: 16), Assim, esse lugar servia para que os sujeitos não só trocassem as roupas, mas também ficassem à contemplação do mar que estava a sua frente, visto que ainda havia uma espaçosa varanda em que eram colocados bancos e poltronas.

Ainda nesse espaço de praia atividades outros momentos de encontro são descritos pelo Guia:

... corridas de cavallos, passeios em carruagens e trolys, jogo de bollas de borracha, cricket, trapesios balanços, velocípedes, volante (lawn-tenis), tirando-se assim partido dos 200 metros de varandas dos camarotes, nas horas impróprias para o banho. (GB, 1890: 16)

O Guia dos Banhistas deixa a praia, e passa a descrever que chama de "Habitações da Villa Sequeira". Passamos, então, para a vida dentro do balneário e o que ela pode oferecer. 


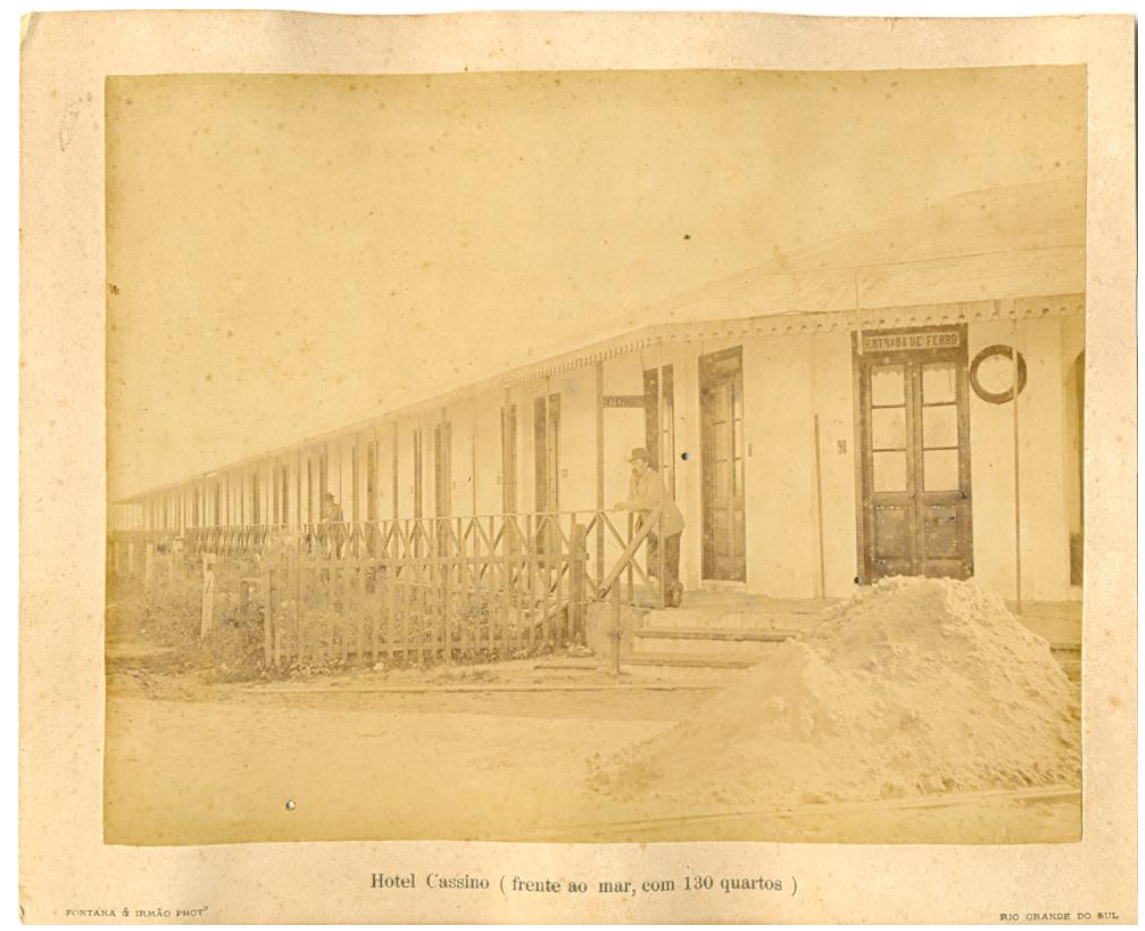

Imagem 4: Hotel Cassino, 1908.

Acervo da Bibliotheca Riograndense.

O hotel local, Hotel Casino, possuía "136 quartos, 8 lojas, salão de jantar, banheiros, water-closets, circumdadas todas estas instalações por 700 metros correntes de varandas cobertas" (GB, 1890: 17).

Além do hotel como paradouro, existia a possibilidade de alugar uma das 40 casas mobiliadas, que possuíam a característica de: “... accommodações para família regular; sala de casa de campo. 3 grandes alcovas, cosinha, área de 19 metros, e portão de serventia ao fundo" (GB, 1890: 17). Pensando também que, para que o gozo do veraneio fosse ainda mais completo, pensando aí em não ter preocupações com as lides diárias de uma casa, a empresa informa no Guia que "já para esta estação" um serviço de lavanderia, cocheiras e leitaria.

Segundo o documento, os preços tanto do hotel, como dessas casas de aluguel, visavam atender as mais variadas economias, sem distinção, daí: 
... o empenho da Companhia em proporcionar á pessoa mais econômica o goso dos banhos do mar, quando é certo que em hotéis de condições menos completas, e nas cidades do Estado, paga-se $5 \$ 000$ por dia, por pessoa. (GB, 1890: 18).

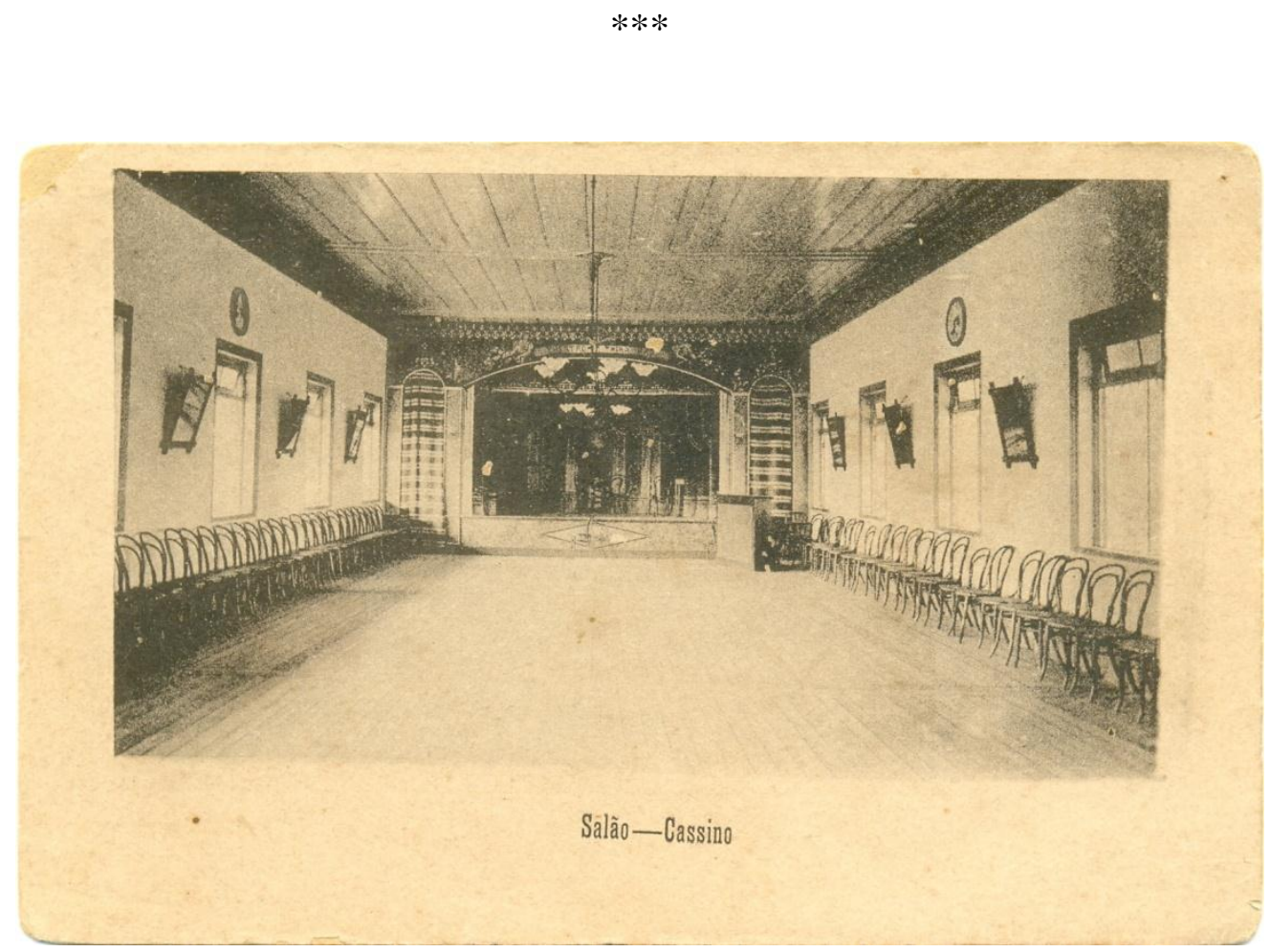

Imagem 5: Salão do Hotel Cassino, 1908

Acervo da Bibliotheca Riograndense

$* * *$

No último item do documento, "Salões de visitas e concertos, e de jogos" fica bastante evidente a idéia da construção de uma sociabilidade balnear, quando anuncia para a próxima estação a abertura de salões de encontro:

É devido a estas installações que a vida na praia se torna agradável; e serão estes salões o rendez-vous dos moços empregados no commércio, que indo na viagem da noite para pernoitarem na 'Villa Sequeira', darão brilho as danças e folguedos em companhia das famílias ali residentes. (GB, 1890: 21)

Ainda se refere nesse item ao salão de visitas, em que este possuirá:

... um piano para dansa, e outro especial para os concertos instrumentaes e vocaes. Será mobiliado no typo de bailante, e terá um pequeno palco para representações. $\mathrm{O}$ salão de jogos terá bilhares, jogo de bagatella, damas dominó, xadrez e mesas para cartas, sala de leitura e para fumantes, e qualquer outro passatempo próprio para homens. (GB, 1890: 21). 
O Guia dos Banhistas chega ao fim com a questão do transporte, que é feito até a praia por tração animal - tendo em vista que a distância a ser percorrida era longa ( 800 metros), tal serviço foi implantado e atendia aos veranistas que se deslocavam do hotel ou de suas residências alugadas - com horários para tal locomoção a partir das quatro horas da manhã até as 10 da noite.

\section{Uma praia que vai além do texto}

Nesse processo, elementos se escondem por trás da escrita, fazem com que o historiador encontre pistas e rastros que sugerem formas específicas de organizar o mundo. Operamos na busca dos espaços e práticas de sociabilidade forjadas nesse cotidiano dos banhos e do veraneio. Interessa-nos, com isso, os arranjos sociais estabelecidos no interior do balneário, procurando mapear os lugares e as formas de sociabilidade exercidas pelos sujeitos.

Ao descrever e analisar esse documento, é preciso levar em consideração que a história é ordenada culturalmente através de diferentes formas, remetendo a Marshal Sahlins:

\footnotetext{
Esquemas culturais são ordenados historicamente, por que em maior ou menor grau, os significados são reavaliados quando realizados na prática. A síntese desses contrários, desdobra-se nas ações criativas dos sujeitos históricos, ou seja, as pessoas envolvidas. Por que, por um lado, as pessoas organizam seus projetos e dão sentido aos objetos partindo das compreensão preexistentes da ordem cultural. Nesses termos, a cultura é historicamente reproduzida na ação. (Sahlins, 2003: 6)
}

A partir dessa proposta de Sahlins, entendemos que o documento funciona como um suporte dessa cultura que é praticada pelos sujeitos, sendo o Guia dos Banhistas como uma organização do universo social de veraneio que reverbera em práticas culturais historicamente verificáveis. Essa cultura de praia se estabelece, porém, não como estática, mas sim dotada de um dinamismo que se impõe nesse processo constante das práticas dos sujeitos históricos que podem ir além do texto, inscrever-se no texto e reelaborá-lo a cada novo veraneio.

Assim, o texto está para nós como um testemunho, um rastro naquele sentido que Paul Ricoeur elabora para dar sentido à prática historiadora. Nas palavras de Ricouer: "partindo da noção de arquivos, depara com a de documento (e dentre os documentos, com a de testemunho) e, daí, remonta ao seu pressuposto epistemológico último: o rastro, precisamente" (Ricoeur, 1994: 196). 
Esses rastros são organizados em forma de arquivos, se transformam em documentos e, por fim, constroem uma intencionalidade que os torna monumentos (Le Goff, 2003). Nesse movimento, que remonta do rastro ao monumento, encontramos no Guia dos Banhistas um arcabouço de informações que é selecionada, transformada em testemunho pela escolha intencional dos agentes envolvidos em seu arquivamento.

Uma organização de mundo é sugerida pelo documento/monumento, uma forma de organizar a memória coletiva dos sujeitos está em curso. Chamamos aqui essas memórias de "memórias de banho".

Essa memória coletiva forjada a partir do documento é importante para leitura que fazemos dele, pois evidencia um quadro coletivo de memória em que os sujeitos estão inseridos, estabelecendo um campo de ação que pode ser investigado pelo historiador. Assim, nos remetemos a clássica contribuição de Maurice Halbwachs, "A Memória Coletiva", no que essa propõe sobre a organização social da memória a partir do conjunto de sujeitos que formam um grupo de lembrança compartilhada

A memória coletiva que aqui estamos lidando, é uma memória forjada por um documento que circulava entre os sujeitos que faziam parte de um grupo que chamamos de "banhistas", assim:

\footnotetext{
Se a memória coletiva tira sua força e sua duração do fato de ter por suporte um conjunto de homens, não obstante eles são indivíduos que se lembram, enquanto membros do grupo (...). Diríamos voluntariamente que cada memória individual é um ponto de vista sobre a memória coletiva, que este ponto de vista muda conforme o lugar que ali ocupo, e que este lugar mesmo muda segundo as relações que mantenho com os outros meios (Halbwachs, 2004: 55).
}

Ao apresentar o lugar em detalhes geográficos ao leitor, o Guia propõe um duplo processo civilizatório que está em curso: o domínio da natureza pelo homem, bem como a pedagogia elaborada para esse corpo que passa a encarar o espaço de praia como ambiente propício à sociabilidade.

No primeiro caso, pelo fato de Rio Grande estar em franco processo de urbanização, complexificação de suas redes sociais com o significativo aumento de estrangeiros fixando residência, indústrias, áreas comerciais atacadistas, cafés, teatros, (Fraga, 2006), a cidade estava inserida em um movimento que, segundo Pesavento (1999) tomou de assalto não só o Rio Grande do Sul, mas o Brasil: a europeização da sociedade. 
A invenção de um balneário, então, estava intrinsecamente ligada a esse momento de criar similaridades com os europeus - notadamente os franceses. A busca de um novo estilo de vida era a tônica dessa sociedade, estilo de vida aqui entendido nos moldes de Simmel interpretado por Waizbort:

\begin{abstract}
a categoria que, que por assim dizer, retrata a realidade de um dado momento, e nesse sentido é um instantâneo, embora aqui momento seja um momento em um processo de longuíssima duração, que é o processo da cultura, vale dizer a própria história da humanidade. Pois o estilo tem a ver com as qualidades, tendências, disposições, efeitos, atmosferas e afinidades fundamentais dos elementos históricos: o estilo é um fenômeno histórico. (Waizbort, 2000: 179)
\end{abstract}

Tal afirmação leva em consideração a leitura simelliana dos efeitos do dinheiro nos estilos de vida. Se pensarmos que a cidade passava por um momento de efervescência industrial, logo, uma grande circulação de capital, encontramos mais um conector dessa busca de novos espaços que se direcionam a um ideal de civilização europeu.

No bojo da criação desse espaço "civilizado", insere-se um processo civilizatório dos hábitos, das maneiras de se comportar em sociedade, em última instância, dos corpos (Elias, 1995). Esse corpo habituado aos pesados trajes de inverno, passa a desembarcar nos meses de janeiro e fevereiro no veraneio que protesta um novo código social $^{6}$.

Remetendo as Mauss, o servi-se desse corpo será modificado no contexto aqui citado, pois assim como qualquer outro elemento da cultura, a atitude corporal tem hábito que lhes são próprios em cada sociedade. (Mauss, 2004). No livro Nú e Vestido, que trata do corpo carioca em relação, Miriam Goldenberg, citando Mauss, diz: “Conforme explica Mauss, o homem não é um produto de seu corpo, mas a todo instante e em todo lugar é ele quem faz de seu corpo um produto de suas técnicas e de suas representações" (apud Goldenberg, 2002: 33).

O que percebemos é justamente essa domesticação do corpo que deve ser preparado - o corpo ideal - para o banho de mar. Levando em consideração que é esse mesmo indivíduo que pratica a sociabilidade de veraneio, que extravasa o espaço de

\footnotetext{
${ }^{6}$ Importante salientar que no ano de 1884 é inaugurada a linha férrea que conectava a cidade de Bagé à Rio Grande. Pensamos que parte dos veranistas é de pessoas que chegam da região do pampa, da campanha marcada pelo rigoroso inverno, dando sentido a idéia de um novo código social que deve ser estabelecido a partir do espaço de praia.
} 
praia, teremos um retrato do tipo de corpo que circula pelo verão do litoral sul. Ou pelo menos, o tipo de corpo ideal dessa virada do século XIX.

Nada de alimentação que não fortaleça o corpo para o encontro com o mar, que gasta energia, exige um corpo fortificado por um bom café da manhã. É preciso se alimentar com carne, ovos e leite fresco para que o corpo agüente a exigência do mar, das corridas na praia que antecipam o banho. Com isso, um padrão de corpo é almejado, e somado a isso as escolhas dos melhores horários que os diferentes sujeitos devem freqüentar o mar.

O horário da manhã é o momento desses corpos robustos, que seguem o padrão que é almejado como qualitativamente positivo para o documento. $\mathrm{O}$ horário da tarde, em contrapartida, é ocupado pelos corpos débeis. O fato é que uma clara distinção de corpos se dá a partir do Guia dos Banhistas, duas categorias são evidenciadas, com isso poderíamos dizer que duas leituras de praia são realizadas.

Uma praia que almeja os corpos saudáveis, fazendo do turno da manhã o momento do encontro desses indivíduos não só com o mar, mas também com os seus "iguais", produzindo uma sociabilidade que se desenvolve nos termos dos favorecidos enquanto "corpos de praia". Acrescentamos que, no turno da manhã, as águas são mais frias, criando um choque maior entre esse corpo que precisa ser, por exemplo, aquecido antes do banho, e o mar. Somente um corpo preparado fisicamente poderia praticar esse tipo de banho, que recebia o nome de "Hidroterápico". Enquanto isso, os corpos débeis precisavam de águas mais quentes, pois seu corpo não suportaria tão impacto desse tipo de banho.

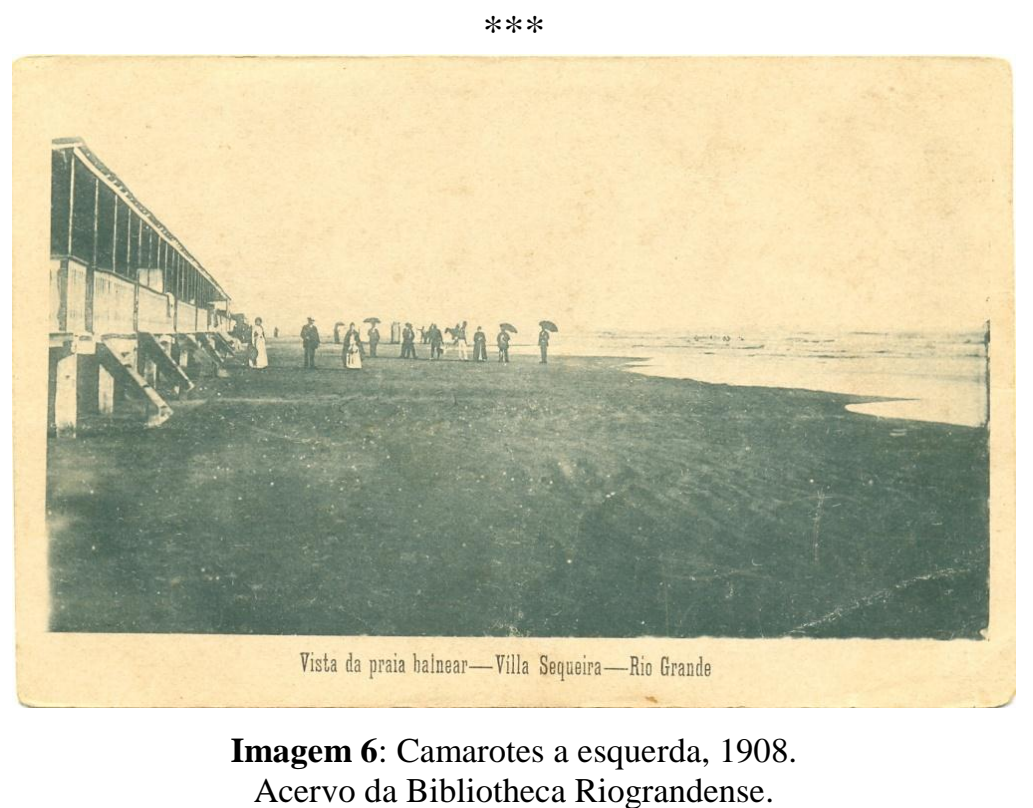

Iluminuras, Porto Alegre, v.12, n. 29, p. 82-98, jul./dez. 2011 
A sociabilidade de praia pode ser sentida a partir dos camarotes, instalados à beira-mar. Mesmo existindo divisões de gênero, a varanda por onde todos circulam é uma só, ou seja, provoca o encontro a todo o momento desses sujeitos. E, na frente desses camarotes, acontecem as atividades esportivas que são elaboradas para os veranistas manterem-se constantemente em ação no espaço de praia.

Tirando os pés da areia, entramos no universo da alameda central que surge no Guia como uma espécie de grande boulevard praiano. Mesmo com casas sendo oferecidas para o aluguel, é inegável que, nesse momento, é o Hotel Cassino que mais atrai os banhistas nessas primeiras temporadas de veraneio.

Com isso, o hotel é local de sociabilidade por excelência. Concentram-se nele os jogos, festas, danças, em suma, um espaço que produz e requer a manutenção de uma sociabilidade incipiente. Ao entender a sociedade, na leitura que Frugoli (2007) faz de Simmel, como uma dos modos pelos quais toda experiência humana pode ser potencialmente organizada e, num sentido concreto, designa um complexo de indivíduos socializados, avançamos ao conceito de sociabilidade que propõe como um de seus fundamentos básicos a conversação.

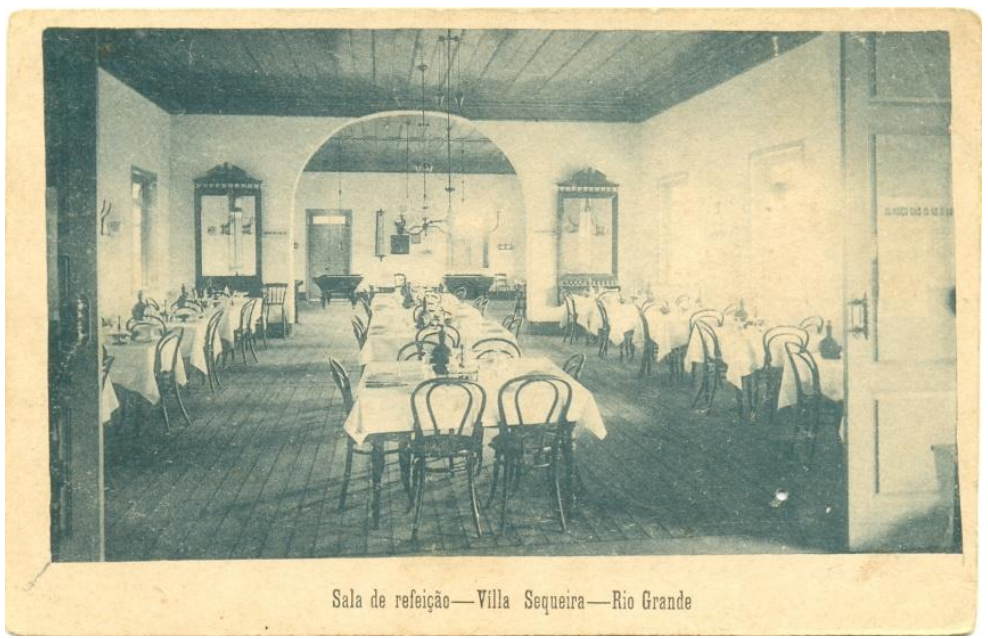

Imagem 7: Interior do Hotel Cassino (sala de refeição), 1908. Acervo da Bibliotheca Riograndense. 
É no Hotel Cassino que os sujeitos exercem esse ato sociativo, estão todos ali partilhando semelhantes interesses temporários de verão, sendo guiados pela mesma rotina (o hotel que dita os horários através, por exemplo, do horário das refeições) e participando dos mesmos eventos que acontecem no interior do local. Por tudo isso, emerge desse momento a conversação enquanto a forma de exercer essa sociabilidade de verão, pois: “Através das trocas de palavras, os participantes zelam pela relação em curso, por meio de regras de amabilidade e etiqueta voltadas à circunscrição de qualquer exacerbação das individualidades" (Frugoli, 2007: 11).

Assim como Simmel, concebemos importante de se notar as formas desse diálogo, o conteúdo não é o propósito, mesmo por que esses sujeitos encontram-se por poucos dias hospedados, não compartilhando de vivências conjuntas anteriores que possibilitem conversas com maiores profundidades. O que resulta desses bailes, jogos, cafés oferecidos no interior do hotel é uma sociedade que se constitui a partir do movimento constante das relações que podem aproximar ou mesmo causar a rejeição entre os indivíduos.

O que se evidencia nesses espaços de veraneio é, para nós, uma unidade no sentido simmeliano. Para o autor, os sujeitos estão sempre em interação, e "a importância desta está no fato de obrigar os indivíduos, que possuem aqueles instintos, interesses, etc, formarem uma unidade - precisamente uma sociedade" (Simmel, 1983: 166).

$\mathrm{Na}$ interação que aqui investigamos, ela se dá como uma interação de praia, em que a sociação se impõe como um valor, uma forma de existência aos sujeitos que ainda desconhecem o cotidiano de um balneário - o "descobrir junto" parece ser a tônica dessas sociações.

É preciso educar esses indivíduos que desembarcam no balneário, os corpos precisam passar por uma pedagogia primeira dos banhos, depois apreender as formas de interação social proporcionadas pelo hotel. Uma espécie de "sociedade da corte", no sentido de teatralização social, se estabelece no litoral sul do Estado, outra maneira de “jogar a sociedade” está em curso na segunda metade do século XIX.

Nesse trajeto que percorremos, encontramos os momentos e as formas de sociabilidade praticadas no Balneário Cassino. Com isso, nos aproximamos daquilo que Elias (1995) chama de momento historicamente verificável no processo civilizatório, 
quando somos capazes de, concretamente, estabelecer um período de ruptura/descontinuidade dentro das estruturas sociais de comportamento.

Assim, encontramos um itinerário que comporta, ao menos, quatros momentos que sugerem algum tipo de sociabilidade.

Pensamos que, ainda no trem se estabelece um primeiro contato entre os veranistas que irão conviver por algum período de tempo. Algum tipo de sociabilidade pode ser forjada: uma apresentação prévia, o conhecimento de como chegou até a escolha desse local, enfim, assuntos preliminares.

Após o trem, o movimento desses sujeitos é o de se deslocar até o hotel, descarregar as malas, se ambientar com os aposentos, conhecer as instalações e os serviços que o local prestará aos seus hóspedes. Os horários do hotel são fundamentais para o entendimento do funcionamento do balneário, pois, para nós, os horários de refeição do hotel ditam os horários da localidade. Funcionam como um relógio biológico que condicionam os hóspedes.

Nesse momento da chegada ao hotel os sujeitos se conhecem, ou, remetendo a viagem de trem, se aproximam mais ainda daqueles que compartilharão a estadia. Um segundo momento já poderá ser estabelecido como passível de uma conversa, um rápido diálogo.

Falta o terceiro e fundamental momento em se tratando de um balneário: os banhos e as ações dentro do espaço de praia. Chegada à hora de tirar os pesados trajes de passeio e vestir a vestimenta de banho - entra em cena a regulação dos corpos - mais leve, propiciando uma efetiva mostra do corpo, que agora está mais leve para as braçadas no mar, para a prática de esportes na beira d'água e para, em ultima instância, ver e ser visto.

Quem está nos camarotes assiste a todo esse processo como um privilegiado espectador, um teatro que se estabelece na beira da praia. Da mesma forma, esse sujeito que está nos camarotes, ocupado por famílias, também está participando de um momento de sociabilidade com quem cruza pela longa varanda que propicia o encontro desses desconhecidos - cada vez menos desconhecidos!

Na praia, então, se abrem duas frentes de contato entre os sujeitos: aqueles que estão com os trajes de banhos, pisando na areia, entrando na água, sendo observados ao praticarem os esportes que o balneário oferece, e aquele outro grupo que prefere os camarotes e os encontros que ele proporciona como um observador aprecia a vista do mar ao invés de mergulhar nele. Porém, não tarda o momento em que os dois grupos 
irão se cruzar, pois efetivamente os que estão no banho de mar precisarão retornar as suas cabines ou as suas barracas (dependendo da escolha de cada família).

Ao retornar ao hotel existe o tempo para o descanso dos corpos, é preciso repor as energias gastadas com o mar e voltar às vestes tradicionais do cotidiano de veraneio. Após essa recomposição desse cenário que parece intermediário chega o momento noturno do hotel.

Agora o salão é aberto, a música começa a tocar e os jogos estão liberados. Existe a oportunidade de divertimento para todos que estão ali, desde bailes, folguedos infantis até os mais "sérios", bem como os espaços em que é preciso dinheiro para entrar, pois a roleta, as cartas, exige remuneração mesmo em um ambiente que parece descompromissado e apenas de lazer.

O que observamos nesse trajeto que os sujeitos realizam, é o fato de que quando cai o sol e a noite chega, eles, de alguma forma já se conhecem, já estabeleceram contatos prévios que, se não trouxe intimidade, ao menos proporcionou um grau menor de estranhamento se assim podemos dizer. $\mathrm{O}$ espaço de sociabilidade por excelência do hotel, seus salões, estão, agora, propensos ao acontecer das relações entre esses sujeitos.

No dia seguinte retiramos o trem desse trajeto, mas abre-se aos veranistas a possibilidade de um maior contato pela avenida principal que foi construída justamente para a prática das caminhadas, dos encontros, da realização da sociabilidade.

\section{Considerações finais}

O Guia dos Banhistas é um testemunho fabricado intencionalmente para compreensão de uma forma de organização social bastante específica: projeto civilizacional, criação de espaços higienizados, novos espaços de lazer, estabelecimento de padrões do corpo de praia, como também formas sociativas. Todos esses elementos em conjunto formando uma memória coletiva das memórias de banho que possuem seu vetor no documento/monumento que aqui analisamos.

Os percursos da sociabilidade de praia foram moldados. Ao perceber esse painel geral que vai do trem ao salão de bailes, encontramos uma espécie de fala dos passos perdidos de verão através dos primeiros banhistas gaúchos do século XIX.

Assim como todo o verão, essa escrita encontra o seu fim, mas com a certeza de que sempre haverá um próximo texto/verão para retornar aos pontos que ainda podem ser explorados por um documento tão cativante ao historiador como é o Guia dos Banhistas. 


\section{Referências}

CORBIN, Alain. Território do Vazio: a Praia no Imaginário Ocidental. São Paulo: Cia das Letras, 1989.

DARTON, Robert. O Grande Massacre de Gatos. Rio de Janeiro: Graal, 1986.

ELIAS, Norbert. O Processo Civilizador: Uma história dos Costumes. Rio de Janeiro: Zahar, 1995.

FRAGA, Solismar. Cidade do Rio Grande: Industrialização e Urbanidade (1873/1990). Rio Grande: FURG, 2006.

FRÚGOLI, Heitor. Sociabilidade Urbana. Rio de Janeiro: Jorge Zahar, 2007. GEERTZ, Clifford. A Interpretação das Culturas. São Paulo: LTC, 1989.

HALBWACHS, Maurice. A Memória Coletiva. São Paulo: Centauro, 1996.

LE GOFF, Jacques. História e Memória. Campinas: Ed. Unicamp, 2003.

MALYSSE, Stephane. "Em busca dos (h)alteres-egos; olhares franceses nos bastidores da corpolatria carioca". In: GOLDENBERG, Mirian. O Nú e o Vestido: Dez antropólogos revelam a cultura do corpo carioca. Rio de Janeiro: Record, 2007.

MAUSS, Marcel. Sociologia e Antropologia. São Paulo: Cosac e Naify, 2004.

MORAES FILHO, Evaristo (org.). Simmel: Sociologia. São Paulo: Ática, 1983.

PESAVENTO, Sandra. O Imaginário da Cidade - Visões literárias do Urbano. Porto Alegre: Editora da Universidade/UFRGS, 1999.

RICOEUR, Paul. Tempo e Narrativa. São Paulo: Papirus, 1994.

SAHLINS, Marchall. Ilhas de História. Rio de Janeiro: Jorge Zahar, 2003.

WAIZBORT, Leopoldo. As aventuras de Simmel. São Paulo: Editora 34, 2000.

Recebido em: 17/12/2010

Aprovado em: 25/03/2011 